\title{
Optic disc topography in Malay patients with normal-tension glaucoma and primary open-angle glaucoma
}

This article was published in the following Dove Press journal:

Clinical Ophthalmology

12 December 2014

Number of times this article has been viewed

\author{
Abdul Rahim Adlina ${ }^{1,2}$ \\ Koh Alisa-Victoria' \\ Ismail Shatriah' \\ Ahmad Tajudin Liza- \\ Sharmini' \\ Mt Saad Ahmad ${ }^{2}$ \\ 'Department of Ophthalmology, \\ School of Medical Sciences, Health \\ Campus, Universiti Sains Malaysia, \\ Kubang Kerian, Kelantan, Malaysia; \\ ${ }^{2}$ Department of Ophthalmology, \\ Hospital Sultanah Bahiyah, Alor Setar, \\ Kedah, Malaysia
}

Background: There are limited data concerning the optic disc topography in normal-tension glaucoma (NTG) and primary open-angle glaucoma (POAG) patients living in Southeast Asian countries. This study aims to compare optic disc parameters in patients with NTG and POAG in Malaysia and to discuss the results in comparison with studies of NTG and POAG in other Asian countries.

Methods: This prospective cross-sectional study was performed in two hospitals with glaucoma service in Malaysia from 2010 to 2012. Seventy-seven patients of Malay ethnicity were enrolled in this study, including 32 NTG patients and 45 POAG patients. Using the Heidelberg Retinal Tomograph III, we measured optic disc area, cup area, rim area, cup volume, rim volume, cupto-disc area ratio, mean cup depth, maximum cup depth, cup shape measure, height variation contour, mean retinal nerve fiber layer thickness, and retinal nerve fiber layer cross-sectional area.

Results: The eyes for NTG patients had significantly larger optic disc areas (2.65 [standard deviation, 0.41] vs 2.40 [standard deviation, 0.36 ] $\mathrm{mm}^{2}$, respectively; $P=0.006$ ) and cup areas (1.54 [standard deviation, 0.43 ] vs 1.32 [standard deviation, 0.40 ] $\mathrm{mm}^{2}$, respectively; $P=0.027$ ) compared with the eyes of POAG patients. Comparison of the other parameters between the two groups revealed no significant difference $(P>0.050)$. The moderate and severe NTG patients showed significantly deeper cups and larger disc and cup areas when compared with the moderate and severe POAG patients $(P<0.050)$.

Conclusion: The NTG patients in this study have notably larger optic disc and cup areas than the POAG patients. Our observations are consistent with those reported in studies of NTG and POAG patients in Korea. The deeper cups and larger disc and cup areas may serve as indicators of severity when comparing NTG with POAG. However, these findings require verification with IOP and visual field results.

Keywords: normal-tension glaucoma, primary open-angle glaucoma, Malay ethnicity, optic disc topography, Heidelberg Retina Topography III

\section{Introduction}

Normal-tension glaucoma (NTG) is more common than primary open-angle glaucoma (POAG) in Northeast Asian countries. The prevalence rate of NTG in Japan and Korea ranges from $2.0 \%$ to $3.6 \%$, whereas the rate of POAG ranges from $0.2 \%$ to $0.8 \% .{ }^{1-5}$ However, the scenario is different in the Southeastern Asian region. The prevalence of NTG was reported to be lower than that of POAG in Malaysia, Thailand, and the Phillipines. ${ }^{6-9}$

The Malay ethnicity represents the third largest ethnic group in Asia and remains the main ethnic group in Malaysia, Indonesia, and Brunei. Previous descriptions of
Correspondence: Ismail Shatriah Department of Ophthalmology, School of Medical Sciences, Universiti Sains Malaysia, 16150 Kubang Kerian, Kelantan, Malaysia

Email shatriah@usm.my 
the appearance of the optic disc in glaucomatous patients have been restricted to studies of Malay people living in Singapore. ${ }^{10-13}$ There are limited data available on glaucoma patients of Malay ethnicity outside of Singapore.

The Heidelberg Retinal Tomograph (HRT) III (Heidelberg Engineering, Heidelberg, Germany) has been widely used to describe the characteristics of the optic disc in glaucoma patients in recent years. ${ }^{14-20}$ Our study aims to investigate the differences in optic disc parameters between NTG and POAG patients of Malay ethnicity in Malaysia, using HRT III analysis.

\section{Methods}

This was a prospective comparative cross-sectional study involving patients with NTG and POAG at two Glaucoma Service Units in Malaysia from November 2010 to February 2012. We recruited 77 Malay patients, including 32 NTG and 45 POAG patients. Approval was obtained from the Ethical Committee of the Ministry of Health, Malaysia, and the Research and Ethical Committee at the School of Medical Sciences, Universiti Sains Malaysia. The study protocol was conducted in accordance with the Declaration of Helsinki on human research. Written informed consent was obtained from all patients in the study.

The study details were described previously. ${ }^{21}$ NTG patients were recruited on the basis of clinical criteria defined by the Collaborative Normal Tension Glaucoma Study, ${ }^{22}$ which included the presence of glaucomatous cupping with a corresponding visual field defect and a median intraocular pressure (IOP) of less than $21 \mathrm{mmHg}$, but never exceeding $24 \mathrm{mmHg}$, in at least 10 readings conducted in either eye.

Patients with POAG were defined as having glaucomatous optic neuropathy in the presence of an open angle and no other ocular abnormality to account for a secondary mechanism. ${ }^{23}$ POAG patients with an IOP of more than $21 \mathrm{mmHg}$ were considered in this study. The subjects recruited in both studied groups were of Malay ethnicity extending back at least two generations, including all parents and grandparents.

For both groups, we excluded patients' congenital and secondary glaucoma, gonioscopic findings of a closed angle, the presence of peripheral anterior synechiae, pseudoexfoliation membrane, angle recession and new vessel formations at the angle, dense media opacity, myopia greater than -6.0 diopter, and a tilted optic disc. Patients with diabetic retinopathy, retinitis pigmentosa, nonglaucomatous optic neuropathy, or central nervous system diseases were also excluded.
All patients underwent a thorough ocular assessment, including evaluation of the visual acuity, refraction, IOP measurements, and anterior segment, as well as funduscopy, gonioscopy, and fundus photograph documentation. IOP phasing was performed in the NTG group. The vertical cup disc ratio was determined on the basis of clinical examination and the evaluation of fundus photographs by an identified glaucoma specialist at both centers. Both groups of patients were further subcategorized as having clinical moderate glaucoma when the vertical cup disc ratio ranged from 0.7 to 0.8 , or clinically advanced glaucoma when the vertical cup disc ratio ranged from 0.9 to fully cupped.

All patients underwent visual field assessment with 24-2 program. An age- and power-adjusted spherical correction was added to the distance refraction to achieve best corrected vision. The loss of visual field was considered significant when three or more congruous nonedge points were present in the typical arcuate area, a depressed pattern deviation plot at a $P<5 \%$ level with at least one point depressed at a $P<1 \%$ level was observed, the corrected pattern standard deviation was significant at the $P<5 \%$ level, and the Glaucoma Hemifield Test was outside the normal limits.

A minimum of two reliable visual field tests was required. The visual field assessments were considered reliable only when the false-positive rate was $15 \%$ or lower, the falsenegative rate was $30 \%$ or lower, and the fixation loss was less than $15 \%$.

The Advanced Glaucoma Intervention Study (AGIS) score was calculated on the basis of the results of the visual field assessment with the 24-2 program (Swedish Interactive Threshold Algorithm standard). All patients were then subcategorized as having mild (1-5 points), moderate (6-11 points), or end-stage impairment of the visual field (12-20 points), according to the score. ${ }^{24}$

All patients underwent the HRT III. The analysis of optic disc topography was performed by an identified investigator at each center. High-quality images were ensured according to the criteria described by Bowd et al. ${ }^{25}$ The data were obtained from the right eye if both eyes were eligible, or from the worse eye in asymmetrical cases.

The data analyses were performed using Predictive Analysis Software statistics version 18.0 (IBM Corporation, Armonk, NY, USA). Demographic and ophthalmic data were compared using an independent $t$-test for continuous variables that were normally distributed. Comparisons between the groups were performed with the Mann-Whitney rank sum test for continuous variables that were not normally distributed. A $P$-value of $<0.05$ was considered statistically significant. 


\section{Results}

A total of 77 patients were included in the study (NTG $n=32$, POAG $n=45)$. The mean ages of the NTG and POAG groups were 64.0 years (standard deviation, 9.3 years) and 64.9 years (standard deviation, 9.2 years), respectively. There was a slightly higher number of women in the POAG group $(55.6 \%)$ compared with in the NTG group $(50.0 \%)$. The severity of glaucoma in both groups was further objectively subcategorized on the basis of the clinical assessment and the AGIS score. These data are summarized in Table 1.

Table 2 presents the comparison of the mean optic disc parameters between the NTG and POAG groups. Patients with NTG had significantly larger disc and cup areas than those with POAG ( $P=0.006$ and $P=0.027$, respectively). The other HRT III parameters such as rim area, cup volume, rim volume, vertical cup/disc ratio, mean cup depth, and mean retinal nerve fiber layer thickness were not significantly different between patients with NTG and those with POAG $(P>0.05)$.

Tables 3 and 4 describe the comparison of the NTG and POAG on the basis of the clinical assessment. The moderately

Table I Demographic and clinical characteristics

\begin{tabular}{|c|c|c|c|}
\hline Characteristic & $\begin{array}{l}\text { NTG } \\
(n=32)\end{array}$ & $\begin{array}{l}\text { POAG } \\
(n=45)\end{array}$ & $P$-value \\
\hline Age, years & & & $0.905^{*}$ \\
\hline Mean \pm SD & $64.0 \pm 9.3$ & $64.9 \pm 9.2$ & \\
\hline Minimum & 45.0 & 45.0 & \\
\hline Maximum & 84.0 & 82.0 & \\
\hline Sex, n (\%) & & & $0.630^{\dagger}$ \\
\hline Female & $16(50.00 \%)$ & $25(55.60 \%)$ & \\
\hline Male & $16(50.00 \%)$ & 20 (44.40\%) & \\
\hline Selected eye, n (\%) & & & $0.685^{\dagger}$ \\
\hline RE & $17(53.10 \%)$ & $26(57.80 \%)$ & \\
\hline LE & 15 (46.90\%) & $19(42.20 \%)$ & \\
\hline Spherical equivalent, D & & & $0.431 *$ \\
\hline Mean \pm SD & $+0.28 \pm 1.63$ & $-0.1 I \pm 1.33$ & \\
\hline$M D, d B$ & & & $0.773 *$ \\
\hline Mean \pm SD & $-10.35 \pm 8.76$ & $-11.27 \pm 8.46$ & \\
\hline CPSD, dB & & & $0.195^{*}$ \\
\hline Mean \pm SD & $5.03 \pm 3.42$ & $6.86 \pm 3.87$ & \\
\hline VCDR, n (\%) & & & $0.307^{\dagger}$ \\
\hline Clinical moderate & 18 (56.25\%) & 20 (44.44\%) & \\
\hline Clinical advanced & 14 (43.75\%) & 25 (55.56\%) & \\
\hline AGIS score, n (\%) & & & $0.222^{\dagger}$ \\
\hline Mild & $10(31.26 \%)$ & 7 (I5.55\%) & \\
\hline Moderate & II (34.37\%) & $16(35.55 \%)$ & \\
\hline Severe-end stage & II (34.37\%) & $22(48.90 \%)$ & \\
\hline
\end{tabular}

Notes: *Independent $t$-test applied. 'Pearson chi-square test applied. Level of significance was set at 0.05 .

Abbreviations: NTG, normal-tension glaucoma; POAG, primary open-angle glaucoma; SD, standard deviation; RE, right eye; LE, left eye; $D$, diopter; MD, mean deviation; CPSD, corrected pattern standard deviation; VCDR, vertical cup-to-disc ratio; AGIS, Advanced Glaucoma Intervention Study. severe NTG patients were noted to present significantly deeper cups compared with their POAG counterparts $(P=0.02)$. Meanwhile, advanced NTG patients had significantly larger cup areas when compared with advanced POAG patients $(P=0.039)$. The other optic nerve head parameters were comparable between the two groups $(P>0.05)$.

The disc area was significantly larger in moderately severe and advanced NTG patients when compared with the POAG patients, based on the AGIS score $(P=0.032$ and $P=0.026$, respectively). These findings are summarized in Tables 5 and 6 . We did not detect any significant difference in this parameter between the group with mild NTG and the group with mild POAG $(P>0.05)$. No significant differences were detected in the other optic nerve head parameters between the two groups, based on severity according to AGIS score $(P>0.05)$.

\section{Discussion}

Table 7 describes the published articles reporting comparisons of optic disc topography between NTG and POAG patients from Asia; the majority of these studies were carried out in Korea and Japan. ${ }^{26-29}$ We were unable to find any other comparison studies on similar topics in other Asian populations. Confocal scanning laser tomography and HRT analysis were used in the previously published studies. ${ }^{26-29}$ HRT III was implemented in our study. Because of the different modalities used in these studies, we intend to compare the observed trends, but we are unable to directly compare the measurement of all parameters between studies.

We observed that the mean disc area in NTG patients was significantly larger compared with in the POAG group. Our observation is consistent with the results of Korean studies. ${ }^{26,27}$ Yang and Park noted that the mean disc area was $2.70 \pm 0.51 \mathrm{~mm}^{2}$ in NTG patients and $2.22 \pm 0.59 \mathrm{~mm}^{2}$ in POAG patients $(P=0.002) .{ }^{26}$ Shin et al reported that the mean disc area was $2.78 \pm 0.48 \mathrm{~mm}^{2}$ in NTG patients and $2.41 \pm 0.58 \mathrm{~mm}^{2}$ in POAG patients $(P=0.001) .{ }^{27}$ In contrast, no significant differences in the mean disc area were detected in NTG and POAG patients from Japan and Italy. ${ }^{28-30}$

Our NTG patients had a significantly larger cup area compared with the POAG patients. This result is in agreement with reports by Shin et al and Kiriyama et al. ${ }^{27,28}$ Shin et al reported that the mean cup area was $1.51 \pm 0.46 \mathrm{~mm}^{2}$ in their NTG patients and $1.11 \pm 0.60 \mathrm{~mm}^{2}$ in POAG patients $(P=0.001) .{ }^{27}$ Kiriyama et al reported a mean cup area of $1.46 \pm 0.58 \mathrm{~mm}^{2}$ in the Japanese patients with NTG and $1.10 \pm 0.55 \mathrm{~mm}^{2}$ with POAG $(P=0.031) .{ }^{28}$ However, Nakatsue et al and Lester and Mikelberg reported that 
Table 2 Comparison of the mean values of the optic disc parameters between NTG and POAG patients

\begin{tabular}{|c|c|c|c|c|c|}
\hline \multirow[t]{2}{*}{ Optic disc parameters } & \multicolumn{2}{|l|}{ Mean \pm SD } & \multirow[t]{2}{*}{ MD $(95 \% \mathrm{Cl})$} & \multirow[t]{2}{*}{$T$ stat $(d f)$} & \multirow[t]{2}{*}{ P-value* } \\
\hline & NTG $(n=32)$ & POAG $(n=45)$ & & & \\
\hline Disc area, $\mathrm{mm}^{2}$ & $2.65 \pm 0.4 I$ & $2.40 \pm 0.36$ & $0.26(0.08-0.44)$ & $2.84(75)$ & 0.006 \\
\hline Cup area, $\mathrm{mm}^{2}$ & $1.54 \pm 0.43$ & $1.32 \pm 0.40$ & $0.22(0.02-0.40)$ & $2.25(75)$ & 0.027 \\
\hline Rim area, $\mathrm{mm}^{2}$ & $1.12 \pm 0.4 \mid$ & $1.07 \pm 0.44$ & $0.05(-0.15-0.24)$ & $0.45(75)$ & 0.651 \\
\hline Cup volume, $\mathrm{mm}^{3}$ & $0.47 \pm 0.28^{\dagger}$ & $0.40 \pm 0.37^{\dagger}$ & - & $-1.32^{\ddagger}$ & $0.187 \pi$ \\
\hline Rim volume, $\mathrm{mm}^{3}$ & $0.23 \pm 0.13$ & $0.21 \pm 0.15$ & $0.02(-0.05-0.08)$ & $0.50(75)$ & 0.617 \\
\hline Cup/disc area ratio & $0.58 \pm 0.14$ & $0.55 \pm 0.15$ & $0.03(-0.04-0.09)$ & $0.72(75)$ & 0.473 \\
\hline Linear cup/disc ratio & $0.76 \pm 0.09$ & $0.74 \pm 0.11$ & $0.02(-0.03-0.07)$ & $0.80(75)$ & 0.425 \\
\hline Mean cup depth, mm & $0.37 \pm 0.09$ & $0.35 \pm 0.13$ & $0.12(-0.03-0.07)$ & $0.74(75)$ & $0.46 \mathrm{I}$ \\
\hline Maximum cup depth, mm & $0.77 \pm 0.16$ & $0.75 \pm 0.23$ & $0.02(-0.07-0.12)$ & $0.44(75)$ & 0.663 \\
\hline Cup shape measure & $-0.04 \pm 0.06$ & $-0.06 \pm 0.06$ & $0.02(-0.0 \mathrm{I}-0.05)$ & $-1.25(75)$ & 0.123 \\
\hline Height variation contour, $\mathrm{mm}$ & $0.39 \pm 0.19^{\dagger}$ & $0.33 \pm 0.15^{\dagger}$ & - & $-1.63^{\ddagger}$ & $0.103 \pi$ \\
\hline Mean RNFL thickness, mm & $0.15 \pm 0.10$ & $0.15 \pm 0.08$ & $0.00(-0.04-0.04)$ & $0.83(75)$ & 0.934 \\
\hline RNFL cross-sectional area, $\mathrm{mm}^{2}$ & $0.88 \pm 0.60$ & $0.83 \pm 0.48$ & $0.05(-0.19-0.30)$ & $0.43(75)$ & 0.670 \\
\hline
\end{tabular}

Notes: *Independent $t$-test was applied. †Median (interquartile range). ${ }^{\dagger} Z$ stat. "Mann-Whitney test was applied. Bold text indicates that the values reached significant level. Abbreviations: NTG, normal-tension glaucoma; POAG, primary open-angle glaucoma; SD, standard deviation; MD, mean difference; Cl, confidence interval; $d f$, degree of freedom; RNFL, retina nerve fiber layer.

there were no significant differences between these two groups. ${ }^{29,30}$ Yang and Park did not mention in their analysis. ${ }^{26}$ A larger optic disc size in NTG patients compared with in patients with other types of glaucoma has also been reported in non-Asian population. ${ }^{31,32}$

We noted that the cup was significantly deeper in the NTG patients compared with the POAG patients, with moderate severity on clinical assessment. However, the disc and cup areas were persistently larger in the groups with advanced disease according to the clinical assessment and AGIS scoring. Thus, we suggest that the cup depth and the disc and cup areas may serve as indicators to differentiate the severity of NTG and POAG. However, this evaluation should also be accompanied by measurements of the IOP and visual field in clinical practice.

The cup-to-disc ratio and other optic nerve head parameters were comparable between the NTG and POAG patients in this study. This observation is in agreement with Shin et al. ${ }^{27}$ Interestingly, Kiriyama et al noted that their NTG patients displayed a significantly smaller mean rim area, thinner mean retinal nerve fiber layer, smaller retinal nerve fiber layer cross-sectional area, larger mean cup volume, and increased mean cup/disc area ratio when compared with $\mathrm{POAG}$ patients. ${ }^{28}$ All optic nerve head parameters were similar between the NTG and POAG groups in the two subsequent studies. ${ }^{29,30}$

Table 3 Comparisons of the optic disc parameters between moderate NTG and POAG patients (based on clinical assessment)

\begin{tabular}{|c|c|c|c|c|c|}
\hline \multirow[t]{3}{*}{ Optic disc parameters } & \multicolumn{2}{|l|}{ Mean \pm SD } & \multirow[t]{3}{*}{ MD (95\% Cl) } & \multirow[t]{3}{*}{ T stat $(d f)$} & \multirow[t]{3}{*}{$P$-value* } \\
\hline & Moderate & Moderate & & & \\
\hline & NTG $(n=18)$ & POAG $(n=20)$ & & & \\
\hline Disc area, $\mathrm{mm}^{2}$ & $2.7 I \pm 0.40$ & $2.49 \pm 0.38$ & $0.22(-0.40-0.48)$ & $1.72(36)$ & 0.095 \\
\hline Cup area, $\mathrm{mm}^{2}$ & $1.38 \pm 0.33$ & I. $17 \pm 0.37$ & $0.21(-0.02-0.44)$ & $1.82(36)$ & 0.076 \\
\hline Rim area, $\mathrm{mm}^{2}$ & $|.33 \pm 0.3|$ & $1.32 \pm 0.44$ & $0.01(-0.25-0.26)$ & $0.07(36)$ & 0.945 \\
\hline Cup volume, $\mathrm{mm}^{3}$ & $0.43 \pm 0.18$ & $0.3 I \pm 0.20$ & $0.12(0.00-0.25)$ & $1.98(36)$ & 0.055 \\
\hline Rim volume, $\mathrm{mm}^{3}$ & $0.30 \pm 0.11$ & $0.28 \pm 0.18$ & $0.02(-0.08-0.12)$ & $0.40(36)$ & 0.694 \\
\hline Cup/disc area ratio & $0.5 I \pm 0.10$ & $0.47 \pm 0.14$ & $0.04(-0.04-0.12)$ & $0.94(36)$ & 0.354 \\
\hline Linear cup/disc ratio & $0.7 I \pm 0.07$ & $0.68 \pm 0.11$ & $0.03(-0.03-0.09)$ & $1.08(36)$ & 0.288 \\
\hline Mean cup depth, mm & $0.37 \pm 0.07$ & $0.30 \pm 0.10$ & $0.07(0.01-0.13)$ & $2.44(36)$ & 0.020 \\
\hline Maximum cup depth, mm & $0.78 \pm 0.24^{\dagger}$ & $0.6 \mathrm{I} \pm 0.25^{\dagger}$ & - & $2.28^{\ddagger}$ & $0.023 \pi$ \\
\hline Cup shape measure & $-0.05 \pm 0.05$ & $-0.08 \pm 0.05$ & $0.03(-0.01-0.06)$ & I.6I (36) & 0.117 \\
\hline Height variation contour, $\mathrm{mm}$ & $0.38 \pm 0.09$ & $0.36 \pm 0.09$ & $0.02(-0.04-0.08)$ & $0.67(36)$ & 0.492 \\
\hline Mean RNFL thickness, mm & $0.21 \pm 0.06$ & $0.19 \pm 0.07$ & $0.03(-0.02-0.07)$ & $1.29(36)$ & 0.207 \\
\hline RNFL cross-sectional area, $\mathrm{mm}^{2}$ & $1.24 \pm 0.35$ & $1.04 \pm 0.43$ & $0.20(-0.06-0.46)$ & I.53 (36) & 0.135 \\
\hline
\end{tabular}

Notes: *Independent $t$-test was applied. ${ }^{\dagger}$ Median (interquartile range). ${ }^{\ddagger} Z$ stat. ${ }^{\top}$ Mann-Whitney test was applied. Bold text indicates that the values reached significant level. Abbreviations: NTG, normal-tension glaucoma; POAG, primary open-angle glaucoma; SD, standard deviation; MD, mean difference; Cl, confidence interval; df, degree of freedom; RNFL, retina nerve fiber layer. 
Table 4 Comparisons of the optic disc parameters between advanced NTG and POAG (based on clinical assessment)

\begin{tabular}{|c|c|c|c|c|c|}
\hline \multirow[t]{2}{*}{ Optic disc parameters } & \multicolumn{2}{|l|}{ Mean \pm SD } & \multirow[t]{2}{*}{ MD (95\% Cl) } & \multirow[t]{2}{*}{ T stat $(d f)$} & \multirow[t]{2}{*}{$P$-value* } \\
\hline & Advanced NTG $(n=14)$ & Advanced POAG $(n=25)$ & & & \\
\hline Disc area, $\mathrm{mm}^{2}$ & $2.58 \pm 0.42$ & $2.3 I \pm 0.37$ & $0.26(0.00-0.53)$ & $2.02(37)$ & 0.050 \\
\hline Cup area, $\mathrm{mm}^{2}$ & $1.74 \pm 0.46$ & $1.44 \pm 0.38$ & $0.29(0.02-0.57)$ & $2.14(37)$ & 0.039 \\
\hline Rim area, $\mathrm{mm}^{2}$ & $0.84 \pm 0.36$ & $0.87 \pm 0.33$ & $-0.03(-0.26-0.20)$ & $-0.26(37)$ & 0.795 \\
\hline Cup volume, $\mathrm{mm}^{3}$ & $0.62 \pm 0.35$ & $0.53 \pm 0.24$ & $0.09(-0.11-0.28)$ & $0.92(37)$ & 0.365 \\
\hline Rim volume, $\mathrm{mm}^{3}$ & $0.11 \pm 0.09 \dagger$ & $0.13 \pm 0.13^{\dagger}$ & - & $-0.95^{\ddagger}$ & 0.340 \\
\hline Cup/disc area ratio & $0.67 \pm 0.13$ & $0.62 \pm 0.13$ & $0.05(-0.04-0.14)$ & I.I3 (37) & 0.264 \\
\hline Linear cup/disc ratio & $0.82 \pm 0.08$ & $0.78 \pm 0.08$ & $0.03(-0.03-0.09)$ & I.10 (37) & 0.277 \\
\hline Mean cup depth, mm & $0.36 \pm 0.11$ & $0.39 \pm 0.13$ & $-0.02(-0.11-0.06)$ & $-0.54(37)$ & 0.593 \\
\hline Maximum cup depth, mm & $0.76 \pm 0.20$ & $0.82 \pm 0.23$ & $-0.06(-0.21-0.09)$ & $-0.86(37)$ & 0.393 \\
\hline Cup shape measure & $-0.02 \pm 0.07^{\dagger}$ & $-0.06 \pm 0.06^{\dagger}$ & - & $-1.39 \ddagger$ & $0.163 \pi$ \\
\hline Height variation contour, $\mathrm{mm}$ & $0.39 \pm 0.24^{\dagger}$ & $0.30 \pm 0.14^{\dagger}$ & - & $-1.20^{\ddagger}$ & $0.229 \pi$ \\
\hline Mean RNFL thickness, mm & $0.10 \pm 0.13^{\dagger}$ & $0.13 \pm 0.10^{\dagger}$ & - & $-1.64^{\ddagger}$ & $0.101 \pi$ \\
\hline RNFL cross-sectional area, $\mathrm{mm}^{2}$ & $0.54 \pm 0.76^{\dagger}$ & $0.70 \pm 0.49^{\dagger}$ & - & $-1.38^{\ddagger}$ & $0.169 \pi$ \\
\hline
\end{tabular}

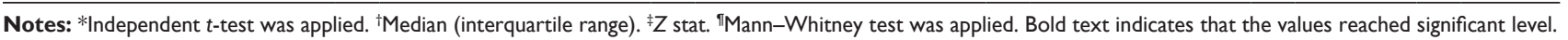
Abbreviations: NTG, normal-tension glaucoma; POAG, primary open-angle glaucoma; SD, standard deviation; $\mathrm{MD}$, mean difference; $\mathrm{Cl}$, confidence interval; df, degree of freedom; RNFL, retina nerve fiber layer.

Table 5 Comparisons of the optic disc parameters between moderate NTG and POAG patients (based on AGIS score)

\begin{tabular}{|c|c|c|c|c|}
\hline \multirow[t]{2}{*}{ Optic disc parameters } & \multicolumn{2}{|c|}{ Median (interquantile range) } & \multirow[t]{2}{*}{ Z stat } & \multirow[t]{2}{*}{$\boldsymbol{P}$-value* } \\
\hline & Moderate NTG $(n=I I)$ & Moderate POAG $(n=16)$ & & \\
\hline Disc area, $\mathrm{mm}^{2}$ & $2.65(0.72)$ & $2.25(0.44)$ & -2.14 & 0.032 \\
\hline Cup area, $\mathrm{mm}^{2}$ & $1.61(0.62)$ & $1.22(0.45)$ & -1.99 & 0.047 \\
\hline Rim area, $\mathrm{mm}^{2}$ & $1.03(0.35)$ & $0.85(0.50)$ & -0.25 & 0.804 \\
\hline Cup volume, $\mathrm{mm}^{3}$ & $0.47(0.26)$ & $0.33(0.23)$ & -0.96 & 0.340 \\
\hline Rim volume, $\mathrm{mm}^{3}$ & $0.35(0.23)$ & $0.22(0.13)$ & -0.86 & 0.389 \\
\hline Cup/disc area ratio & $0.51(0.17)$ & $0.53(0.16)$ & -1.07 & 0.284 \\
\hline Linear cup/disc ratio & $0.72(0.11)$ & $0.73(0.11)$ & -1.01 & 0.311 \\
\hline Mean cup depth, mm & $0.35(0.12)$ & $0.30(0.10)$ & -0.08 & 0.939 \\
\hline Maximum cup depth, mm & $0.77(0.27)$ & $0.62(0.17)$ & -0.08 & 0.939 \\
\hline Cup shape measure & $-0.04(0.10)$ & $-0.08(0.05)$ & $-0.6 \mathrm{I}$ & 0.540 \\
\hline Height variation contour, $\mathrm{mm}$ & $0.37(0.10)$ & $0.34(0.07)$ & -1.19 & 0.236 \\
\hline Mean RNFL thickness, mm & $0.19(0.14)$ & $0.16(0.09)$ & $-1.6 \mid$ & 0.108 \\
\hline RNFL cross-sectional area, $\mathrm{mm}^{2}$ & $\mathrm{I} .23(0.79)$ & $0.84(0.50)$ & -1.40 & 0.163 \\
\hline
\end{tabular}

Notes: *Mann-Whitney test was applied. Bold text indicates that the values reached significant level.

Abbreviations: NTG, normal-tension glaucoma; POAG, primary open-angle glaucoma; RNFL, retina nerve fiber layer; AGIS, Advanced Glaucoma Intervention Study.

Table 6 Comparisons of the optic disc parameters between advanced-stage NTG and POAG (based on AGIS score)

\begin{tabular}{|c|c|c|c|c|}
\hline \multirow[t]{2}{*}{ Optic disc parameters } & \multicolumn{2}{|c|}{ Median (interquantile range) } & \multirow[t]{2}{*}{ Z stat } & \multirow[t]{2}{*}{ P-value* } \\
\hline & Severe NTG $(n=I I)$ & Severe POAG $(n=22)$ & & \\
\hline Disc area, $\mathrm{mm}^{2}$ & $2.47(0.60)$ & $2.28(0.4 I)$ & -2.22 & 0.026 \\
\hline Cup area, $\mathrm{mm}^{2}$ & $1.66(0.61)$ & $\mathrm{I} .40(0.57)$ & -1.58 & 0.114 \\
\hline Rim area, $\mathrm{mm}^{2}$ & $0.81(0.34)$ & $0.85(0.50)$ & -1.43 & 0.152 \\
\hline Cup volume, $\mathrm{mm}^{3}$ & $0.63(0.44)$ & $0.55(0.45)$ & -1.80 & 0.071 \\
\hline Rim volume, $\mathrm{mm}^{3}$ & $0.12(0.09)$ & $0.13(0.13)$ & -1.14 & 0.256 \\
\hline Cup/disc area ratio & $0.67(0.15)$ & $0.63(0.20)$ & -0.07 & $0.94 I$ \\
\hline Linear cup/disc ratio & $0.82(0.09)$ & $0.80(0.13)$ & -0.07 & 0.941 \\
\hline Mean cup depth, mm & $0.36(0.13)$ & $0.39(0.24)$ & -1.78 & 0.075 \\
\hline Maximum cup depth, mm & $0.77(0.24)$ & $0.83(0.40)$ & $-1.3 \mid$ & 0.191 \\
\hline Cup shape measure & $-0.02(0.07)$ & $-0.05(0.10)$ & -1.34 & 0.180 \\
\hline Height variation contour, $\mathrm{mm}$ & $0.38(0.24)$ & $0.32(0.15)$ & -0.89 & 0.373 \\
\hline Mean RNFL thickness, mm & $0.09(0.14)$ & $0.13(0.10)$ & -1.29 & 0.198 \\
\hline RNFL cross-sectional area, $\mathrm{mm}^{2}$ & $0.52(0.77)$ & $0.70(0.53)$ & -1.68 & 0.093 \\
\hline
\end{tabular}

Notes: *Mann-Whitney test was applied. Bold text indicates that the values reached significant level.

Abbreviations: NTG, normal-tension glaucoma; POAG, primary open-angle glaucoma; RNFL, retina nerve fiber layer; AGIS, Advanced Glaucoma Intervention Study. 


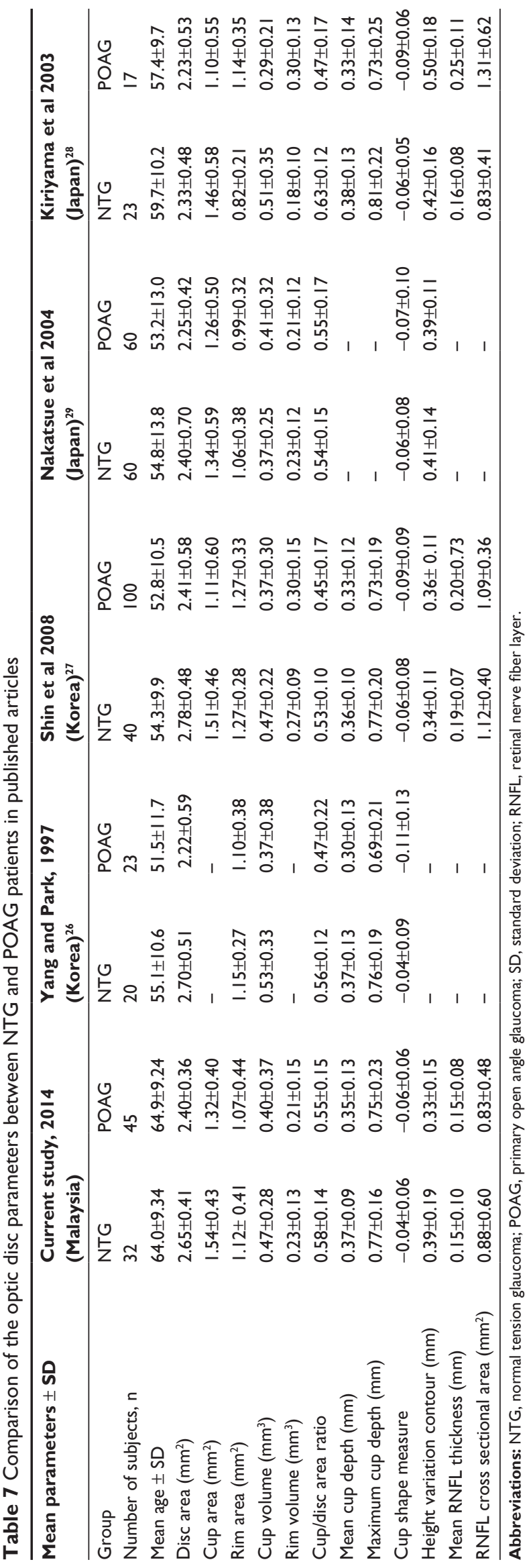

In conclusion, our findings support the existing data on optic disc parameters in NTG and POAG patients from other Asian countries. Our NTG patients had deeper cups and larger optic disc and cup areas in comparison with the POAG patients. These parameters may serve as important optic disc characteristics to differentiate moderate NTG or POAG from the advanced stages of these diseases. However, measurement of IOP and visual field analysis are still the main indicators in clinical practice.

\section{Disclosure}

The authors report no conflict of interest in this work.

\section{References}

1. Shiose Y, Kitazawa Y, Tsukahara S, et al. Epidemiology of glaucoma in Japan - a nationwide glaucoma survey. Jpn J Ophthalmol. 1991;35(2): $133-155$.

2. Iwase A, Suzuki Y, Araie M, et al; Tajimi Study Group, Japan Glaucoma Society. The prevalence of primary open-angle glaucoma in Japanese: the Tajimi Study. Ophthalmology. 2004;111(9):1641-1648.

3. Lee JB, Cho YS, Choe YJ, Hong YJ. The prevalence of glaucoma in Korean adults. J Korean Ophthalmol Soc. 1993;34(1):65-69.

4. Kim JH, Kang SY, Kim NR, et al. Prevalence and characteristics of glaucoma among Korean adults. Korean J Ophthalmol. 2011;25(2): 110-115.

5. Kim CS, Seong GJ, Lee NH, Song KC; Namil Study Group, Korean Glaucoma Society. Prevalence of primary open-angle glaucoma in central South Korea the Namil study. Ophthalmology. 2011;118(6): 1024-1030.

6. Reddy SC, Tajunisah I, Low KP, Karmila AB. Prevalence of eye diseases and visual impairment in urban population - a study from University of Malaya Medical Centre. Malaysian Fam Physician. 2008;3(1):25-28.

7. Selvarajah S. An analysis of glaucoma patients seen at the General Hospital Kuala Lumpur over a five year period: 1986 to 1990. Med J Malaysia. 1998;53(1):42-45.

8. FlorCruz NV, Joaquin-Quino R, Silva PAS, et al. Profile of glaucoma cases seen at a tertiary referral hospital. Philipp J Ophthalmol. 2005; 30(4):161-165.

9. Sothornwit N, Jenchitr W, Pongprayoon C. Glaucoma care and clinical profile in Priest Hospital, Thailand. J Med Assoc Thai. 2008;91(Suppl 1): S111-S118.

10. Shen SY, Wong TY, Foster PJ, et al. The prevalence and types of glaucoma in malay people: the Singapore Malay eye study. Invest Ophthalmol Vis Sci. 2008;49(9):3846-3851.

11. Tan GS, Wong TY, Fong CW, Aung T; Singapore Malay Eye Study. Diabetes, metabolic abnormalities, and glaucoma. Arch Ophthalmol. 2009; 127(10):1354-1361.

12. Perera SA, Wong TY, Tay WT, Foster PJ, Saw SM, Aung T. Refractive error, axial dimensions, and primary open-angle glaucoma: the Singapore Malay Eye Study. Arch Ophthalmol. 2010;128(7):900-905.

13. Zheng Y, Wong TY, Lamoureux E, et al. Diagnostic ability of Heidelberg Retina Tomography in detecting glaucoma in a population setting: the Singapore Malay Eye Study. Ophthalmology. 2010;117(2):290-297.

14. Burgansky-Eliash Z, Wollstein G, Bilonick RA, Ishikawa H, Kagemann L, Schuman JS. Glaucoma detection with the Heidelberg retina tomograph 3. Ophthalmology. 2007;114(3):466-471.

15. Townsend KA, Wollstein G, Danks D, et al. Heidelberg Retina Tomograph 3 machine learning classifiers for glaucoma detection. Br J Ophthalmol. 2008;92(6):814-818.

16. Xiao GG, Wu LL. Optic disc analysis with Heidelberg Retina Tomography III in glaucoma with unilateral visual field defects. Jpn J Ophthalmol. 2010;54(4):305-309. 
17. Jindal S, Dada T, Sreenivas V, Gupta V, Sihota R, Panda A. Comparison of the diagnostic ability of Moorfield's regression analysis and glaucoma probability score using Heidelberg retinal tomograph III in eyes with primary open angle glaucoma. Indian J Ophthalmol. 2010;58(6):487-492.

18. Sato S, Hirooka K, Baba T, Shiraga F. Comparison of optic nerve head parameters using Heidelberg Retina Tomograph 3 and spectral-domain optical coherence tomography. Clin Experiment Ophthalmol. 2012;40(7): 721-726.

19. Häntzschel J, Terai N, Sorgenfrei F, Haustein M, Pillunat K, Pillunat LE. Morphological and functional differences between normal-tension and high-tension glaucoma. Acta Ophthalmol (Copenh). 2013;91(5):e386-e391.

20. Kourkoutas D, Buys YM, Flanagan JG, et al. Clinical significance of optic disc progression by topographic change analysis maps in glaucoma: an 8-year follow-up study. J Ophthalmol. 2014;2014:987389.

21. Adlina AR, Shatriah I, Liza Sharmini AT, Ahmad MS. Optic disc topography of normal tension glaucoma patients in Malaysia. Med J Malaysia. 2013;68(4):338-342.

22. Collaborative Normal-Tension Glaucoma Study Group. Comparison of glaucomatous progression between untreated patients with normaltension glaucoma and patients with therapeutically reduced intraocular pressures. Am J Ophthalmol. 1998;126(4):487-497.

23. Foster PJ, Buhrmann R, Quigley HA, Johnson GJ. The definition and classification of glaucoma in prevalence surveys. Br J Ophthalmol. 2002; 86(2):238-242.

24. Advanced Glaucoma Intervention Study. 2. Visual field test scoring and reliability. Ophthalmology. 1994;101(8):1445-1455.
25. Bowd C, Balasubramanian M, Weinreb RN, et al. Performance of confocal scanning laser tomograph Topographic Change Analysis (TCA) for assessing glaucomatous progression. Invest Ophthalmol Vis Sci. 2009; 50(2):691-701.

26. Yang JG, Park KH. A comparison of optic nerve head topography in primary open-angle glaucoma and normal-tension glaucoma in Korean. Korean J Ophthalmol. 1997;11(2):79-83.

27. Shin IH, Kang SY, Hong S, et al. Comparison of OCT and HRT findings among normal, normal tension glaucoma, and high tension glaucoma. Korean J Ophthalmol. 2008;22(4):236-241.

28. Kiriyama N, Ando A, Fukui C, et al. A comparison of optic disc topographic parameters in patients with primary open angle glaucoma, normal tension glaucoma, and ocular hypertension. Graefes Arch Clin Exp Ophthalmol. 2003;241(7):541-545.

29. Nakatsue T, Shirakashi M, Yaoeda K, et al. Optic disc topography as measured by confocal scanning laser ophthalmoscopy and visual field loss in Japanese patients with primary open-angle or normal-tension glaucoma. J Glaucoma. 2004;13(4):291-298.

30. Iester M, Mikelberg FS, Courtright P, Drance SM. Correlation between the visual field indices and Heidelberg retina tomograph parameters. J Glaucoma. 1997;6(2):78-82.

31. Burk ROW, Rohrschneider K, Noack H, Völcker HE. Are large optic nerve heads susceptible to glaucomatous damage at normal intraocular pressure? A three-dimensional study by laser scanning tomography. Graefes Arch Clin Exp Ophthalmol. 1992;230(6):552-560.

32. Tuulonen A, Airaksinen PJ. Optic disc size in exfoliative, primary open angle, and low-tension glaucoma. Arch Ophthalmol. 1992;110(2): 211-213.
Clinical Ophthalmology

\section{Publish your work in this journal}

Clinical Ophthalmology is an international, peer-reviewed journa covering all subspecialties within ophthalmology. Key topics include: Optometry; Visual science; Pharmacology and drug therapy in eye diseases; Basic Sciences; Primary and Secondary eye care; Patient Safety and Quality of Care Improvements. This journal is indexed on

Submit your manuscript here: http://www.dovepress.com/clinical-ophthalmology-journal

\section{Dovepress}

PubMed Central and CAS, and is the official journal of The Society of Clinical Ophthalmology (SCO). The manuscript management system is completely online and includes a very quick and fair peer-review system, which is all easy to use. Visit http://www.dovepress.com/ testimonials.php to read real quotes from published authors. 